\title{
OSTEOPETROSIS ASSOCIATED WITH FAMILIAL PARAPLEGIA: REPORT OF A FAMILY
}

\author{
By Skip Jacques*, M.D., John T. Garner, M. D., David Johnson, M.D. and \\ C. HunTer SHELdEN, M. D. \\ Departments of Neurosurgery and Radiology, Huntington Memorial Hospital, Pasadena, Ca., \\ and the Huntington Institute of Applied Medical Research, Pasadena, Ca., U.S.A.
}

Abstract. A clinical analysis of three members of a family with documented osteopetrosis and familial paraplegia is presented. All patients had a long history of increased bone density and slowly progressing paraparesis of both legs. A thorough review of the literature has revealed no other cases which presented with paraplegia without spinal cord compression. Although the etiologic factor or factors remain unknown, our review supports the contention that this is a distinct clinical entity.

IN 1904, a German radiologist, Heinrich Albers-Schonberg, described a 26-yearold man with multiple fractures and generalised sclerosis of the skeleton. The disease has henceforth commonly been known as Albers-Schonberg disease or marble osteopetrosis, a term first introduced by Karshner in 1922 . Other eponyms are bone disease, osteosclerosis fragilis generalisata, and osteopetrosis generalisata. Approximately 300 cases had been reported in the literature by 1968. It has been generally accepted that the disease presents in two distinct forms, an infantile progressive disease and a milder form in childhood and adolescence. The two forms differ clinically and genetically. A dominant pattern of inheritance is usually seen in the benign type whereas the severe infantile form is usually inherited as a Mendelian recessive. This important distinction has not been well emphasised. The reported cases are almost equally divided between the two types.

The disease is essentially one of abnormal bone development and is characterised by increased thickness and density of cortical and spongy bone. The more severe forms of the disease show evidence of decreased haematopoiesis and secondary anaemia. Multiple neurological dysfunctions have been reported but, to the best of our knowledge, paraplegia has not been described as part of the syndrome. In the progressive infantile variety survival past the first year of life is rare. Cranial nerve pressure is frequent if the foramina of the skull fail to enlarge during growth. Blindness and deafness may ensue. These infants usually develop hepatosplenomegaly and anaemia and pursue a rapid downhill course. The haemolytic anaemia and thrombocytopenia are probably related to the hypersplenism as favourable clinical responses have been reported with corticosteroids and splenectomy.

\section{CASE REPORTS}

Case I. J. L. is a 65-year-old white male with a history of progressive spastic paraparesis since the age of 25 , first presenting as slowness and awkwardness of gait. He is now confined to a wheelchair. Family history revealed his father, one brother, and a daughter *Boswell Fellow, Department of Biology, California Institute of Technology, Pasadena, Ca., U.S.A.

Address reprint requests to Skip Jacques, M.D., Huntington Institute of Applied Medical Research, 734 Fairmount Avenue, Pasadena, California 9I I05, U.S.A.

$$
\text { I3/3-B }
$$


as having similar problems. Abnormally dense bones on roentgenographic examination were first noted in 1952. Physical examination revealed marked spasticity of the lower extremities with scissoring and bilateral equinus deformities. There was generalised wasting of the muscles in both lower extremities without fasciculations presenting a typical 'stork leg' appearance. Deep tendon reflexes in both lower extremities were increased with positive Babinski response bilaterally. No ankle clonus was obtained secondary to marked ankylosis. Sensory examination was normal except for decreased position sense in both legs. Both upper extremities were of good strength. Cranial nerve examination revealed wasting of left facial musculature and a markedly atrophic left sternocleidomastoid muscle. The remaining cranial nerves were normal. There was no retinal pigmentation. There was marked pitting oedema of both legs and ulceration of both medial malleoli. The bladder was distended. The prostate was enlarged. Electromyography was consistent with an upper motor neuron lesion of both lower extremities, with no involvement of the upper extremities. Bone biopsy was performed and confirmed osteopetrosis. Plain films of the lumbar spine revealed a minimal decrease in the sagittal diameter of the neural canal. Myeolgraphy demonstrated an hour-glass deformity at all levels and apparent narrowing of the cord itself. There was a free flow of contrast media at all levels. Because the myelogram revealed no structural lesion responsible for the paraplegia, and because of the unusual family history, it was hypothesised that the paraplegia was genetic in origin and that no surgery was indicated. Urinary retention continued. Subsequently, the patient underwent an uneventful transurethral prostatectomy as a result of which urinary function improved. Because of the intriguing family history and interesting findings in this man we decided to investigate other members of his immediate family. The results of our investigation are as listed below.

Case 2. D. T. is the $3 \mathrm{I}$-year-old white female daughter of Case I. She has a history of progressive paraparesis since age 9 , first presenting with incoordination of gait. She has also developed equinus deformities bilaterally. Interestingly, between the ages of I I and I4 the patient claims to have had multiple episodes of facial palsy with involvement of both sides at least two times. There is subjective facial weakness. Examination revealed a tall female with a spastic gait and feet held at equinus at rest. There was mild peripheral facial palsy. The rest of the cranial nerve examination was normal. Electromyographic examination was consistent with an upper motor neuron lesion limited to the lower extremities. X-ray of the chest revealed dense bones consistent with a diagnosis of osteopetrosis. Myelography displayed spinal cord atrophy without obstruction of the subarachnoid space by bone.

Case 3. C. L. is the 78-year-old brother of Case I. He has a history of progressive spasticity of both lower extremities for approximately is years. Flexion contractures of the hips and knees and bilateral equinus deformities are present. He was admitted to another hospital in I970, at which time the osteopetrosis was observed but not recognised as such, the report simply stating ' $\mathrm{X}$-ray of the lumbar spine revealed the bones to show marked increase in density'. Myelography was performed and revealed diffuse spondylosis and a decreased AP diameter of the neural canal. No further studies were obtained because of his age and general debility. Interestingly, both Cases I and 3 had diabetes of adult onset which was well controlled with oral hypoglycaemic agents.

\section{DISCUSSION}

The mode of inheritance of osteopetrosis has been confused for many years. A hereditary pattern was first recognised by Allen in 1939 with differing degrees 
of clinical severity. Johnston et al. (I968) described two modes of inheritance; a dominant form with a rather benign course, and a recessive form which ran a malignant course with marked anaemia, myeloid metaplasia, infection, and frequent early death.

Reports that followed Albers-Schonberg's original description were based primarily on radiographic criteria. Probably many diseases that could produce increased bone density such as leukaemia, myelofibrosis, and fluorosis were included in the same syndrome at that time. However, even with the inclusion of what may be termed phenocopies, it soon became evident that there was a remarkably high familial incidence and that there was some consanguinity in the parents of some patients. The first case of what must have been the dominantly inherited form of the disease was reported in 1922 by Ghormley. In 1926, Karshner collected 22 cases of osteopetrosis with the two cases reported by Ghormley included. The first reliable report of transmission affecting more than one child in successive generations was presented by Pirie in 1930. A mother and three children were affected, the youngest child diagnosed radiographically in utero. However, multiple cases were later reported in successive generations. The dominant and recessive forms of the disease were correctly interpreted and the clinical and genetic significance of two different modes of inheritance were recognised. More recently the clinical-genetic classification of the disease has been expanded into four types. However, for simplicity's sake, it is reasonable to speak of the clinical form of the disease as occurring primarily in two types; the dominant, usually with a severe prognosis, and the recessive, with a relatively benign course. Most authors agree that expression varies only slightly within families and that unrelated families usually demonstrate considerable difference of clinical expression. It is generally conceded that non-penetrance of osteopetrosis probably occurs and this complicates the genetic evaluation of the trait within a given family. Until this report, neither form has been genetically linked to a third trait.

Clinical Manifestations. These may vary considerably. However, as previously described, it is usually practical to distinguish between the benign and the malignant type of Albers-Schonberg's disease. In the malignant type, obliteration of the bone marrow eventually leads to severe anaemia with resulting extramedullary haematopoiesis and secondary hepatosplenomegaly. Optic atrophy, facial palsy, deafness, mental retardation, and multiple fractures of the long bones often complete the typical clinical picture. The disease follows a malignant course and death is usually imminent within a few months, or a few years.

In the benign type numerous variations of the clinical picture occur. Haematologic symptoms seldom appear and a normal life span can be expected in most instances. The patients commonly present a leonine appearance with some macrocephaly and enlargement of the mandible. They are usually tall, with clubbing of the long bones, genu valgum, and coxa vara. Proptosis can occur. Most patients have normal intelligence. Acute facial nerve palsies identical to Bell's palsy may appear in childhood. One author described a unilateral paralysis present at birth. Conductive deafness may occur within a few years due to bony involvement of middle ear structures. Vestibular disturbances are rarely reported.

Normal development is usually retarded in the severe form of osteopetrosis. Hydrocephalus and bossing of the frontal bones may be present. Fractures are common following minor trauma. However, callus formation and bone healing 


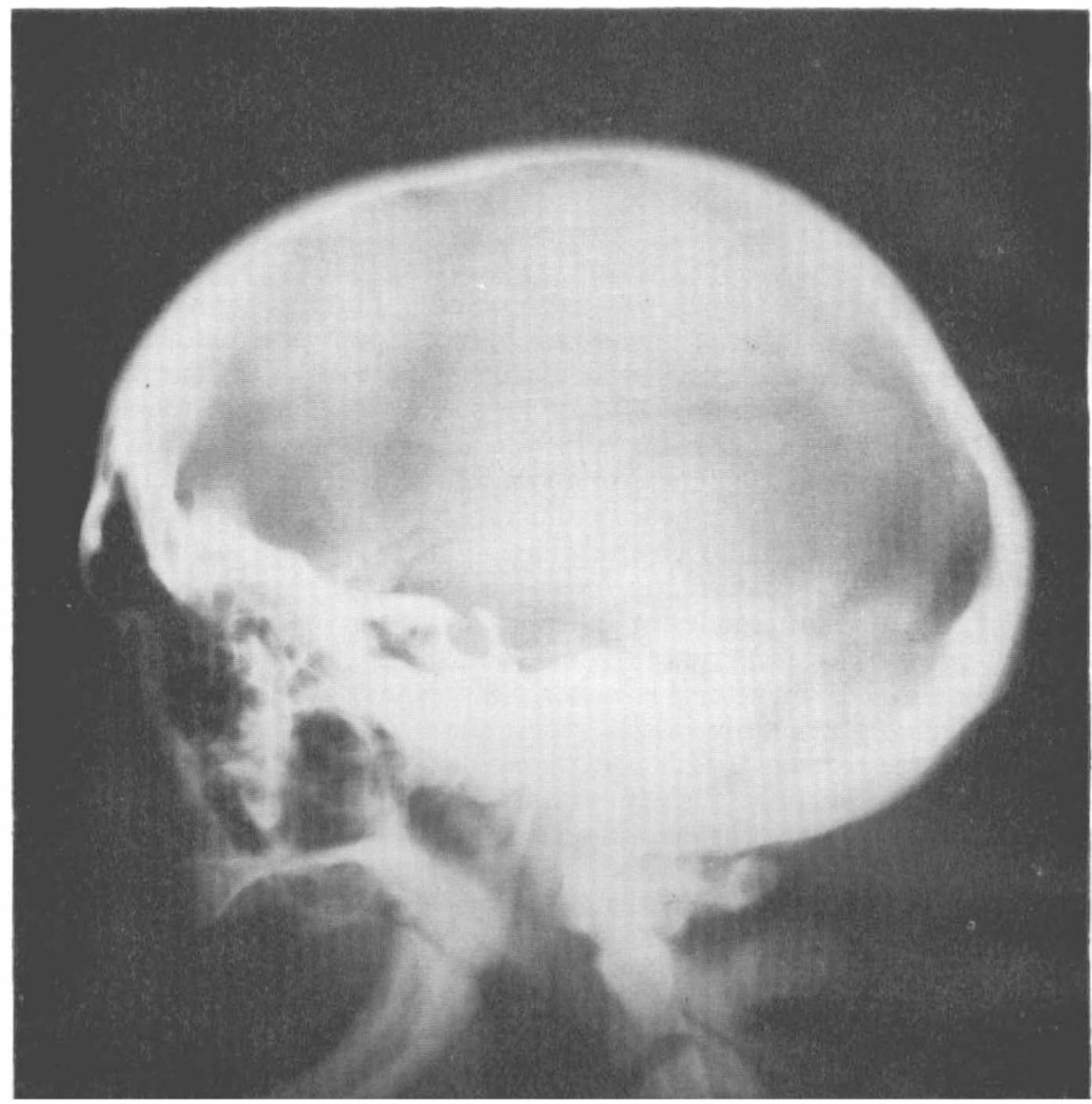

FIG. I

appear to be normal. Intercurrent infections are common in the severe form because of the severely debilitated state. X-ray films usually show widespread skeletal involvement.

The benign form of the disease is not recognised in all patients. There are often no distinguishing clinical features in the disease except an increased number of fractures and carious teeth. Osteomyelitis of the mandible can occur and has been stressed in many reports.

Radiographic Features. Radiologic findings have been the classical basis for establishing the diagnosis (figs I and 2). These findings vary according to the extent, type, and severity of the disease and it is not unusual for a diagnosis to be made serendipitously when an X-ray is requested for a complaint not rèlated to the syndrome. The bones of the skull demonstrate a homogenous pottery type of 


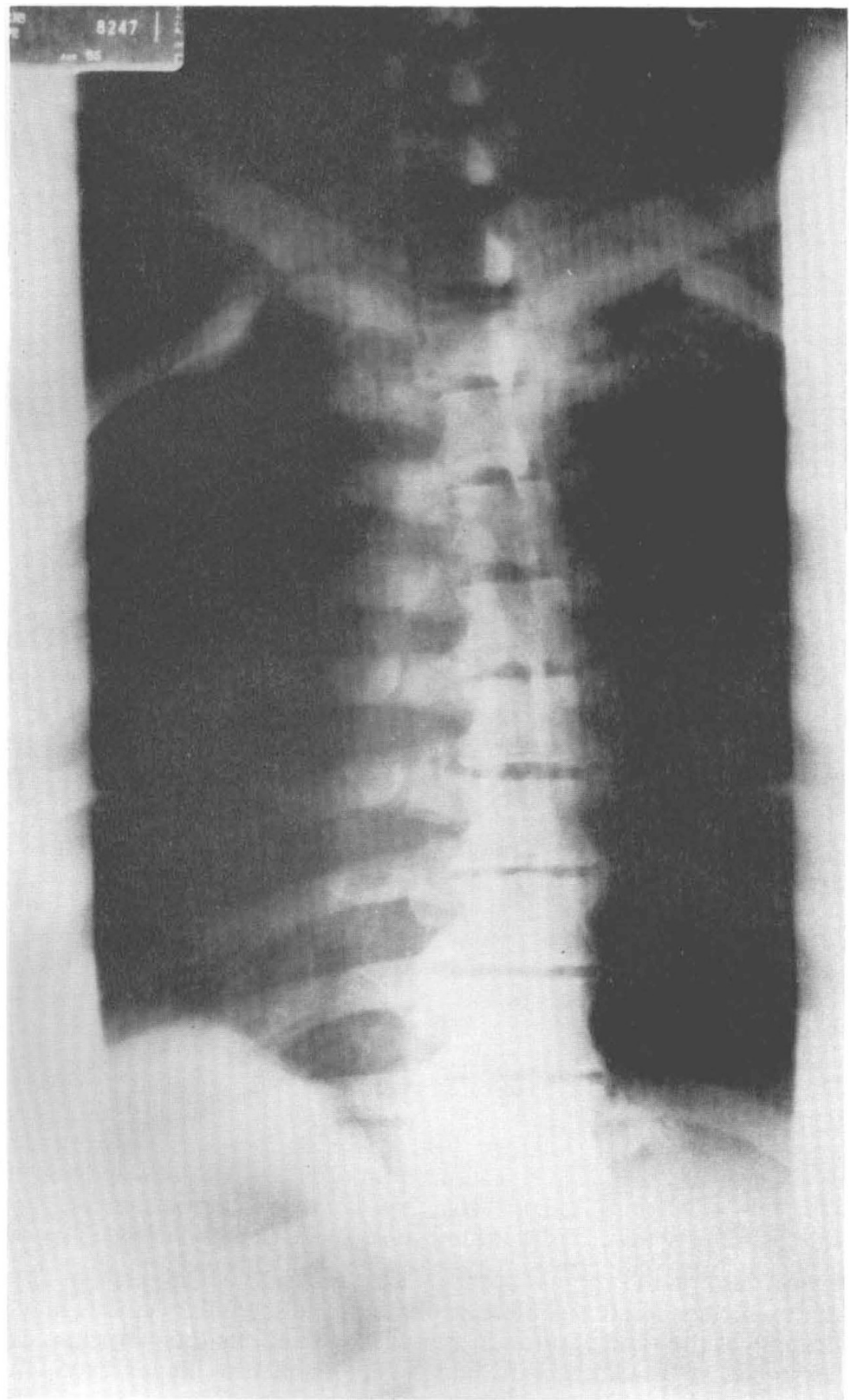

FIG. 2 


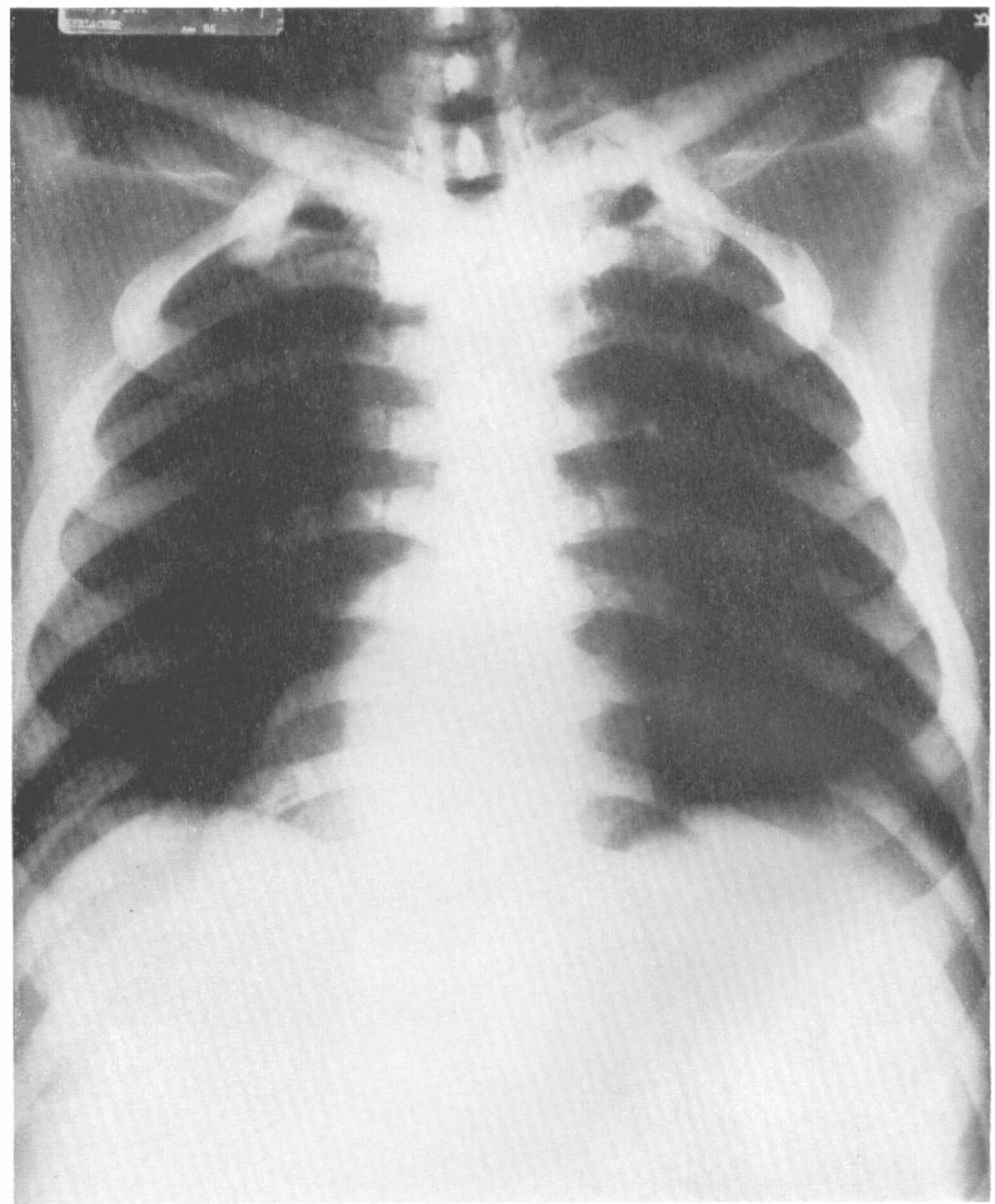

FIG. 3

density with loss of the diploic spaces. Differentiation between the bone components, i.e., cortex, epiphysial plate, spongiosa, and medullary cavity, may be lost. The thickness of the skull is often increased and in adults the calvarium can be as much as $3 \mathrm{~cm}$. in thickness. Although any bone can be involved, the most commonly affected are the long bones, pelvis, bodies of the vertebrae, ribs, and base of the skull. The pituitary fossa is often small. The posterior clinoids are 
thickened. The optic foramina are sometimes constricted with dense margins. Roentgenograms of the hand may reveal terminal tuft erosion. The fragility of the affected bones and their tendency to fracture increased. Abnormal or absent fingernails and syndactyly occur frequently.

Differential diagnosis includes those diseases that have radiographic features in common with osteopetrosis. These include cranial metaphysial dysplasia, Engelmann's disease, erythroblastosis fetalis, congenital syphilis, lead and phosphorus poisoning, metastatic neoplasm, myeloid metaplasia, fibrous dysplasia, generalised familial hyperostosis, chronic renal disease with hyperostosis, hypervitaminosis $\mathrm{A}$, hypervitaminosis $\mathrm{D}$, fluorine intoxication, osteosclerosis, myelosclerosis, malarial ostosis, osteopoikilosis, osteopathia striatum, hepatic infantile hypercalcaemia and, especially, pyknodysostosis.

Because of the marked similarity of the two diseases pyknodysostosis deserves further discussion. This is an inherited disorder of the bone characterised by short stature, persisting cranial sutures, dysplasia of skull bones, flattened mandibular angle, partial aplasia of the terminal phalanges, and increased bone density observed roentgenographically. These patients are also predisposed to fractures. The disease is usually transmitted as an autosomal recessive trait. However, in rare cases the presence of bone abnormalities in the parents suggests that the gene may be partially expressed in a heterozygous state or that more than one genetic locus may determine similar disorders. Common to most cases of pyknodysostosis are the short stature (usually less than five feet), short limbs, open anterior fontanelles, persisting cranial sutures, hypoplastic facial bones, persistent deciduous teeth, increased obtuseness of the angle of the mandible, narrow thorax, clavicles present but incompletely formed, and tapered distal phalanges of fingers and toes.

Laboratory Features. Anaemia is a characteristic finding in dominant osteopetrosis. It is severe in the dominant infantile form and mild in the adult form. Bone marrow biopsies reveal compromised haematopoiesis. Frequently fibrous tissue is found in the marrow. In all of the cases studied by Johnston (I968) the acid phosphatase was markedly elevated. However, excretion of hydroxyproline was within normal range. This suggests that these patients are resorbing bone at a normal rate. It has recently been suggested that thyrocalcitonin may play a part in the aetiology of the disease. Of special interest is the recent report by Verdy et al., (I97I) who describe a 38-year-old female patient with medullary carcinoma of the thyroid. At least four of her nine children has osteopetrosis. Medullary carcinoma of the thyroid is associated with increased production and circulation of calcitonin. This fact, plus the suggestion that an increase in secretion of calcitonin might be responsible for impaired resorption of bone in osteopetrosis, led Verdy to postulate a genetic relationship between medullary carcinoma and osteopetrosis. Of further interest is the report by Krook et al. (1969) of dietary calcium ultimobranchial tumours and osteopetrosis in the bull. A biochemical defect present in the organic matrix of the growth cartilage has also been implicated.

\section{PATHOLOGY}

Sclerotic changes are usually present in the involved bones. There is an increase in the size of trabeculae and, generally, in the regularity of the bone 
structure. Medullary spaces are found to contain foetal primitive bone which has not undergone absorption. Haversian canals are usually enlarged. As previously stated, in response to parathyroid hormone the bone seems to turn over at a normal rate by an increased rate of resorption.

\section{NEUROLOGIC MANIFESTATIONS OF OSTEOPETROSIS}

Many of the clinical manifestations of osteopetrosis can be explained by the impingement of the hard bone on the nerves and blood vessels as they leave the foramina. A frequent finding in osteopetrosis is ocular involvement with optic atrophy. This is thought to be secondary to narrowing of the optic foramina. In bovine experimental animals optic nerve atrophy has been produced by narrowing of the optic foramina. In addition to optic nerve atrophy other ocular disorders such as ophthalmoplegia, nystagmus, exophthalmus, and dilated retinal vessels may be present. Papilloedema may also occur secondarily. A detailed study by Keith (I968) suggests that primary retinal atrophy is also possible and sheds new insight into the neurologic complications of the disease. Heretofore, Keith found the foramina within normal limits. In some of his patients with optic nerve and retinal degeneration there was neither narrowing of the optic canals nor pressure on the optic chiasm or tract. He postulated that the atrophy was secondary to calcium effects on the permeability of membrane due to the greatly increased absorption of calcium from the gut. He also speculated on an association between vitamin A and osteopetrosis as vitamin A deficiency causes thick cancellous bone to be formed instead of compact bone.

Facial paralysis is also a frequent neurological manifestation of osteopetrosis. Of sudden or insidious onset, it frequently occurs in childhood and, as previously described, may even be present at birth. It may fluctuate in severity for the first few years before progressing to total facial paralysis and muscle wasting. Yarington et al. (1967) have advocated relief by endotemporal decompression of the facial nerves. Deafness is also common in osteopetrosis and probably results from more than one mechanism. One may be the previously described interference in the conductive aspect of auditory function as the external auditory canal becomes narrowed by the thickened bone, and otosclerosis may occasionally be present. Also, the cochlear nerve may become constricted as it passes through the petrous temporal bone causing a perceptive type of hearing defect. Trigeminal nerve involvement can also occur. The lesion may be bilateral or unilateral, most often with impairment of the first and second divisions but, occasionally, there can be weakness of the muscles of mastication. Trigeminal neuralgia has also been reported. Anosmia may occur. A review of the literature reveals that the 9th, Ioth, IIth, and I2th nerves are rarely, if ever, involved in this disorder. With the degree of involvement in the basal part of the skull usually seen in osteopetrosis, this is surprising.

Hydrocephalus has repeatedly been shown to occur in osteopetrosis. However, it must not be confused with the macrocephaly which commonly accompanies this syndrome. The mechanism by which hydrocephalus is produced is not entirely clear. Some authors have offered the explanation that it results from impairment of the venous drainage of the brain. This, they suggest, occurs when the jugular foramen of the skull becomes narrowed. Although theoretically this could happen, it seems unlikely and it is certainly not a well-accepted cause of 
hydrocephalus. It must also be recalled that hydrocephalus occurs in the presence of other bone anomalies such as platybasia. It may be that a malformed posterior fossa interrupts the normal circulation of CSF.

Headache is a common complaint in osteopetrosis and may be related to aspects previously discussed. Convulsions have occasionally been observed. Intelligence is dependent upon the genetic type. Patients with the dominantly inherited infantile type are often demented. In the recessively inherited adult type, patients usually have normal mentation.

To our knowledge, a familial type with paraplegia of gradual onset and progression has never been previously described.

\section{TREATMENT OF OSTEOPETROSIS}

Treatment is primarily palliative and symptomatic. Various decompressive procedures for specific nerve involvement have been advocated. Dietary treatments, medical regimens, etc. have been, for the most part, unsuccessful and may be dangerous if patients suffer other metabolic disturbances as a result of the unbalanced diet.

\section{SUMMARY}

The work contains a clinical analysis of three members of one family with a documented proof of osteopetrosis combined with familia paraplegia. All patients had a long history of increasing bone density. No other cases of this sort and combination could be found in literature anywhere.

\section{RÉSUMÉ}

On présente une analyse clinique de trois membres d'une famille souffrant d'ostéopétrose documentée et de paraplégie familiale. Tous les malades avaient une longue histoire de densité osseuse accrue et de paraparèse des deux jambes en lente progression. Une étude approfondie de la littérature n'a pas révélé d'autres cas présentant de la paraplégie sans compression de la moelle épinière. Bien que le ou les facteur(s) étiologique(s) restent inconnus, notre revue appuie l'affirmation qu'il s'agit d'une entité clinique distincte.

\section{ZUSAMMENFASSUNG}

Die Arbeit enthält eine klinische Analyse von drei Mitgliedern einer Familie mit dokumentierter Osteopetrosis kombiniert mit familiärer Paraplegie. Alle Patienten hatten eine lange Vorgeschichte von zunehmender Knochendensität. Keine andern Fälle dieser Kombination konnte in der Literatur gefunden werden.

\section{REFERENCES}

BAIRD, P. A. et al. (1968). Congenital osteopetrosis: An unusual cause of hydrocephalus. Canad. Med. Ass. F. 98, 362.

Blitz, R. \& Pellegrino, E. (1965). Avian osteopetrotic bone. F. Bone and foint Surgery, $47,1365$.

Ed. Thyrocalcitronin: Relation to disease. (1968). N.E.F.M, 278, 56r.

Ellis, P. \& JACKSON, W. (1962). Osteopetrosis. A clinical study of peptic nerve involvement. Am. F. Ophthal. 53, 943.

Elmore, S. M. (1967). Pycnodysostosis: A review. F. Bone and foint Surgery, 49-A, 153. Emani-Ahari, Z. et al. (1969). Pycnodysostosis. F. Bone and foint Surgery, 5I-B, 307. 
Gellis, S. \& Feingold, M. (1967). Pycnodysostosis. Am. F. Dis. Child. II3, 275.

Gomez, L. et al. (I966). The jaws in osteopetrosis. Report of a case. F. Oral Surgery, 24, 67.

Grünebaum, M. \& Landau, D. (I968). Pycnodysostosis. Fr. F. Radiol. 41, 359.

HAMERSMA, H. (I970). Osteopetrosis of the temporal bone. Laryngoscope, Oct., I 5 I 8.

Haymovits, A. \& Rosen, J. (I970). Calcitonin: Its nature and role in man. Pediatrics, 45, I33.

Hinds, E. (1970). Noninflammatory bone disease. $\mathcal{F}$. Oral Surgery, 28, 27.

Johnston, C., JR. et al. (I968). A clinical, genetic, metabolic, and morphologic study of the dominantly inherited benign form. Medicine, 47, I49.

Jones, M. \& MulCAHY, N. (I968). Osteopathia striata, osteopetrosis, and impaired hearing. Arch. Otolaryngol. 87, i 16.

KeIth, C. G. (I968). Retinal atrophy in osteopetrosis. Arch. Ophthal. 79, 234.

Konigsmark, B. (I969). Hereditary deafness in man (3rd of 3 parts). N.E.F.M. 281, 827.

KROOK, L., LUTwALs, L. \& MCENTEE, R. (I969). Dietary calcium, ultimobranchial tumors, and osteopetrosis in the bull. Syndrome of calcitonin excess? Am. F. Clin. Nutr. 22, I I5.

Little, K. (1969). Nature of osteopetrosis. Br. Med. F. 2, 49

MADDS, S., JR. (I969). The parafollicular cell of the thyroid gland as the source of an osteoblast-stimulating factor. F. Bone and Foint Surgery, 5I-A, 875.

Management of metabolic bone disease. (1969). Br. Med. F. 621 .

Moss, A. \& MAInZER, F. (1970). Osteopetrosis: An unusual case of terminal-tuft erosion. Radiology, 97, 631.

Morrow, G., III et al. (1967). Calcium movilization in osteopetrosis. Amer. F. Fis. Child. II4, I6I.

SAHA, M. et al. (I970). Osteopetrosis with spondylolysis-four cases in one family. $B r . \mathcal{F}$. Radiol. 43, 738.

Sedano, H. D., et al. (1968). Pycnodysostosis. Clinical and genetic considerations. Amer. F. Dis. Child. I16, 70.

Thompson, R. D., et al. (I969). Manifestations of osteopetrosis. F. Oral Surgery, $27,63$.

Thyrocalcitonin. (1967). Br. Med. F. 3, 256.

TRAPNell, D. (I968). Peridontal manifestations of osteopetrosis. Br. F. Radiol. $41,669$.

VERDY, M. et al. (I97I). Plasma calcitonin activity in a patient with thyroid medullary carcinoma and her children with osteopetrosis. f. Clin. Endocr. 32, 2 I 6.

WALKER, D. (I966). Counteraction to parathyroid therapy in osteopetrotic mice as revealed in the plasma calcium level and ability to incorporate ${ }^{3} \mathrm{H}$-Proline into bone. Endocrinology, 79, 836.

YARINGTON, C. \& SPRINKLE, P. (1967). Facial palsy in osteopetrosis. Relief by endotemporal decompression. F.A.M.A. 6, 213.

Yu, J. S. et al. (I97I). Osteopetrosis. Arch. Dis. in Childhood, 46, 257. 